\title{
GAMBARAN PERUBAHAN BERAT BADAN PADA AKSEPTOR KB PIL DI BPM FAULIEN PALEMBANG TAHUN 2019
}

\author{
Untari Anggeni \\ Program Studi DIII Kebidanan \\ STIKES Mitra Adiguna Palembang \\ Komplek Kenten Permai Blok J 9-12 Kel. Bukit Sangkal Palembang \\ Email : untarianggeni@gmail.com
}

\begin{abstract}
Abstrak
Kontrasepsi Pil saat ini adalah salah satu metode kontrasepsi yang paling banyak digunakan. Pil kontrasepsi oral kombinasi berisi hormone estrogen dan progesterone. Salah satu efek samping dari kontrasepsi pil adalah peningkatan berat badan. Tujuan penelitian adalah untuk mengetahui gambaran perubahan berat badan pada akseptor KB Pil di BPM Faulien Palembang tahun 2019. Desain penelitian menggunakan jenis deskriptif. Populasi penelitian adalah akseptor pil di BPM Faulien dan yang menjadi sampel penelitian adalah 35 akseptor pil di BPM Faulien Palembang dengan teknik accidental sampling, pengumpulan data dengan menggunakan lembar wawancara. Hasil penelitian menunjukkan Sebagian besar responden dengan umur 20-35 tahun yaitu 77,1\%, pendidikan SMA yaitu 40\%, jumlah anak 2 yaitu 51,4\%, tidak bekerja yaitu 71,5\%, menggunakan pil kombinasi yaitu 65,7\%, mengalami perubahan berat badan yaitu 68,6\%, jumlah kenaikan berat badan responden 4-5 kg yaitu 45,9\%, sebagian besar akseptor mini pil mengalami perubahan berat badan $>5 \mathrm{~kg}$ yaitu 100\%, dan sebagian besar akseptor pil kombinasi mengalami perubahan berat badan 4-5 kg yaitu 81,8\%. Penting untuk meningkatkan konseling KB mengenai efek samping dari kontrasepsi pil yaitu perubahan berat badan.
\end{abstract}

Kata kunci : Perubahan berat badan, kontrasepsi pil

\begin{abstract}
Contraception The current pill is one of the most widely used contraceptive methods. Combined oral contraceptive pills contain estrogen and progesterone. One side effect of contraceptive pills is to increase body weight. The research design uses descriptive types. The study population was pill acceptors in BPM Faulien and the study sample was 35 pill acceptors in BPM Faulien Palembang with accidental sampling technique, collecting data using interview sheets. The results showed that the majority of respondents aged 20-35 years were $77.1 \%$, high school education was $40 \%$, the number of children 2 was $51.4 \%$, not working was $71.5 \%$, using combination pills of $65.7 \%$, changes in body weight were 68.6\%, the number of respondents increased weight 4-5 kg which is 45.9\%, most of the minipil acceptors experienced changes in body weight> $5 \mathrm{~kg}$ which is $100 \%$, and most combination pill acceptors experienced changes in body weight $4-5 \mathrm{~kg}$, which is $81.8 \%$. It is important to improve family planning counseling regarding the side effects of contraceptive pills, namely changes in body weight.
\end{abstract}

Keywords : Changes in body weight, pill contraception 


\section{PENDAHULUAN}

Kontrasepsi hormonal merupakan kontrasepsi yang mengandung hormon estrogen dan atau progesteron yang diberikan pada peserta KB untuk mencegah terjadinya kehamilan, komponen estrogen dapat memberikan efek pertambahan berat badan ekibat restensi cairan, sedangkan komponen progestin memberikan efek pada nafsu makan dan berat badan akan bertambah besar (Sriwahyuni, 2012).

Penggunaaan alat kontrasepsi hormonal dalam jangka waktu tertentu dapat menimbulkan berbagai efek samping salah satunya adalah perubahan berat badan. Namun demikian, berat badan yang bertambah umunya tidak terlalu besar, hal ini bervariasi antara kurang dari $1 \mathrm{~kg}$ sampai $5 \mathrm{~kg}$ dalam tahun pertama. Sebagian besar wanita dari pasangan usia subur yang merupakan akseptor pengguna alat kontrasepsi mengalami peningkatan berat badan (Hartanto, 2015).

Salah satu jenis kontrasepsi efektif yang ada sekarang memungkinkan wanita atau pasangan untuk memilih kontrasepsi yang paling sesuai untuk keadaan mereka sendiri saat ini yang menjadi pilihan adalah kontrasepsi hormonal adalah pil, suntikan, implant (Manuaba, 2012).

Lama pemakaian alat kontrasepi hormonal berhubungan dengan resiko kegemukan. Pada pemakaian konrasepsi hormonal lebih dari satu tahun resiko kegemukan meningkat 1.36 kali dari resiko ini akan mengalami peningkatan setiap pertambahan tahunnya pada pemakaian lebih dari tujuh tahun resiko kegemukan akan meningkat 8,3 kali pada pemakai alat kontrasepsi hormonal. Kegemukan ini terjadi karena adanya penambahan berat badan yang secara terus-menerus (Sugiharti dkk, 2005).

Salah satu kontrasepsi yang popular di Indonesia adalah Pil. Pil yang sering digunakan adalah Pil Oral Kombinasi, Pil Progestin (Mini Pil). Pada beberapa wanita pertambahan berat badan memang disebabkan oleh kontrasepsi oral. Pil oral dapat menaikkan berat badan dari 5-10 kg atau lebih (Hartanto, 2015).

Diagnosa dari pertambahan berat badan pada pemakaian Pil Oral yaitu retensi cairan karena progestin atau estrogen di dalam Pil Oral, pertambahan berat badan yang disebabkan oleh estrogen mengakibatkan bertambahnya lemak subkutan terutama pada pinggul; paha; dan payudara; ini tampak setelah beberapa bulan minum Pil Oral, nafsu makan yang bertambah dan makan banyak (efek anabolik) disebabkan efek androgenik dari progestin, kadar insulin darah meninggi yang disebabkan oleh hormon progestin di dalam Pil Oral. (Hartanto, 2015). Sifat khas kontrasepsi hormonal dengan komponen estrogen menyebabkan pemakainya mudah tersinggung, tegang, retensi air dan garam, berat badan bertambah, menimbulkan nyeri kepala, perdarahan banyak saat menstruasi, meningkatkan pengeluaran leukorea, menimbulkan perlunakan serviks. Sedangkan dengan komponen progesterone menyebabkan payudara tegang, akne (kukulan), kulit dan rambut kering. (Manuaba, 2012).

Efek samping kontrasepsi pil yang paling tinggi frekuensinya yaitu peningkatan berat badan. Penyebab pertambahan berat badan tidak jelas. Untuk mendapatkan gambaran nyata tentang kejadian peningkatan berat badan yang dialami akseptor kontrasepsi pil maka perlu dilakukan suatu penelitian untuk mengetahui sejauh mana pengaruh kontrasepsi suntik dengan peningkatan berat badan. Data yang ada di BPM Faulien Palembang tentang data pengguna KB hormonal dari tahun 2016 sampai 2018, diketahui pada 1 Januari - 31 Desember 2016, jumlah peserta KB berjumlah 2.750 orang. Pengguna kontrasepsi suntikan 1 bulan sebanyak 495 orang (18\%), KB suntikan 3 bulan sebanyak 501 orang $(18,2 \%), \mathrm{KB}$ pil sebanyak 1.632 orang $(59,3 \%)$, dan KB implant sebanyak 122 orang $(4,4 \%)$. Pada 1 Januari - 31 
Desember 2017 jumlah peserta KB berjumlah 2600 orang pengguna kontrasepsi suntikan 1 bulan sebanyak 505 orang(13,1\%), KB suntikan 3 bulan sebanyak 495 orang(12,8\%), KB pil sebanyak 1500 orang (39\%), dan KB implant sebanyak 100 orang $(2,6 \%)$. Pada 1 Januari - 31 Desember 2018 jumlah peserta berjumlah 2733 orang pengguna kontrasepsi suntikan 1 bulan sebanyak 490 orang (13,3\%), KB suntikan 3 bulan sebanyak 505orang $(13,8 \%)$, KB pil sebanyak 1638 orang $(44,7 \%)$ dan $\mathrm{KB}$ implant sebanyak 100 orang $(2,7 \%)$.

Berdasarkan dari latar belakang di atas maka peneliti tertarik untuk melakukan penelitian yang berjudul "Gambaran Perubahan Berat Badan Akseptor KB Pil di BPM Faulien Palembang Tahun 2019”.

\section{METODE PENELITIAN}

\section{Jenis Penelitian}

Penelitian ini jenis deskriptif kualitatif dengan tujuan untuk membuat gambaran perubahan berat badan pada akseptor KB Pil secara objektif.

\section{Waktu dan Tempat Penelitian}

Penelitian dilakukan pada bulan Mei dan Juni 2019 di BPM Faulien Palembang.

\section{Target/Subjek Penelitian}

Sampel penelitian ini adalah sebagian akseptor KB pil yang ada di BPM Faulien.

\section{Data}

Penelitian ini menggunakan data primer yang diperoleh langsung dari responden untuk mengetahui perubahan berat badan pada akseptor pil melalui wawancara dengan menggunakan kuesioner.

\section{Teknik Analisis Data}

Analisis univariat dilakukan untuk melihat distribusi frekuensi perubahan berat badan pada akseptor KB Pil.

\section{HASIL PENELITIAN DAN \\ PEMBAHASAN}

\author{
Distribusi $\quad$ Karakteristik Subjek \\ Penelitian \\ 1. Umur
}

Tabel 1.

Distribusi Responden Berdasarkan Umur

\begin{tabular}{cccc}
\hline No. & Umur & $\mathrm{f}$ & $(\%)$ \\
\hline 1. & $20-35$ tahun & 27 & 77,1 \\
2. & $>35$ tahun & 8 & 22,9 \\
\hline & Total & 35 & 100 \\
\hline
\end{tabular}

Sumber: Data Primer

Berdasarkan tabel 1. dapat diketahui umur responden pada kelompok kasus yang paling dominan adalah umur antara 20-35 tahun, yaitu sebanyak 27 responden $(77,1 \%)$.

\section{Pendidikan}

Tabel 2. Distribusi Responden Berdasarkan Pendidikan

\begin{tabular}{cccc}
\hline No & Pendidikan & f & \% \\
\hline 1. & SD & 5 & 14,3 \\
2. & SMP & 6 & 17,1 \\
3. & SMA & 14 & 40 \\
4. & $>$ SMA & 10 & 28,6 \\
\hline & Total & $\mathbf{3 5}$ & $\mathbf{1 0 0}$ \\
\hline
\end{tabular}

Sumber: Data Primer

Berdasarkan tabel 2. dapat diketahui bahwa sebagian besar responden memiliki pendidikan SMA yaitu $40 \%$.

\section{Paritas}

Tabel 3. Distribusi Responden Berdasarkan Paritas

\begin{tabular}{cccc}
\hline No. & Paritas & f & $\%$ \\
\hline 1. & 1 anak & 13 & 37,1 \\
\hline 2. & 2 anak & 18 & 51,4 \\
\hline 3. & 3 anak & 4 & 11,4 \\
\hline & Total & 35 & 100 \\
\hline
\end{tabular}


Sumber: Data Primer

Berdasarkan tabel 3 dapat diketahui bahwa sebagian besar responden dengan jumlah anak 2 yaitu $51,4 \%$.

\section{Pekerjaan}

Tabel 4. Distribusi Responden Berdasarkan Pekerjaan

\begin{tabular}{cccc}
\hline No. & Pekerjaan & F & $\%$ \\
\hline 1. & Ya & 10 & 28,5 \\
2. & Tidak & 25 & 71,5 \\
\hline & Total & 35 & 100 \\
\hline
\end{tabular}

Sumber: Data Primer

Berdasarkan tabel 4 dapat diketahui bahwa sebagian besar responden tidak bekerja yaitu $71,5 \%$.

\section{Jenis Pil KB}

Tabel 5. Distribusi Responden Berdasarkan Jenis Pil

\begin{tabular}{cccc}
\hline No. & Pil KB & f & $\%$ \\
\hline 1. & Minipil & 12 & 34,3 \\
2. & Pil Kombinasi & 23 & 65,7 \\
\hline & Total & 35 & 100 \\
\hline
\end{tabular}

Sumber: Data Primer

Berdasarkan tabel 5 dapat diketahui bahwa sebagian besar responden menggunakan pil kombinasi yaitu $65,7 \%$.

\section{Perubahan Berat Badan}

Tabel 6. Distribusi Responden Berdasarkan Perubahan Berat Badan

\begin{tabular}{cccc}
\hline No. & $\begin{array}{c}\text { Perubahan } \\
\text { BB }\end{array}$ & F & $\%$ \\
\hline 1. & Ya & 24 & 68,6 \\
2. & Tidak & 11 & 31,4 \\
\hline & Total & 35 & 100 \\
\hline
\end{tabular}

Sumber: Data Primer
Berdasarkan tabel 6. menunjukkan sebagian besar akseptor mengalami perubahan berat badan yaitu $68,8 \%$.

Tabel 7. Distribusi Responden Berdasarkan Jumlah Perubahan Berat Badan

\begin{tabular}{cccc}
\hline No. & Kenaikan & $\mathrm{F}$ & $\%$ \\
\hline 1. & $1-2 \mathrm{~kg}$ & 6 & 25 \\
2. & $2-3 \mathrm{~kg}$ & 4 & 16,6 \\
3. & $4-5 \mathrm{~kg}$ & 11 & 45,9 \\
4. & $>5 \mathrm{~kg}$ & 3 & 12,5 \\
\hline \multicolumn{2}{c}{ Total } & 24 & 100
\end{tabular}

Sumber: Data Primer

Berdasarkan tabel 7. tersebut dapat diketahui bahwa sebagian besar akseptor mengalami perubahan berat badan $4-5 \mathrm{~kg}$ yaitu $45,9 \%$.

Tabel 8. Distribusi Perubahan Berat Badan Akseptor berdasarkan Jenis Pil KB

\begin{tabular}{|c|c|c|c|c|c|c|}
\hline \multirow{3}{*}{$\begin{array}{c}\text { Perubahan } \\
\text { BB }\end{array}$} & \multicolumn{4}{|c|}{ Jenis Pil } & \multirow[t]{3}{*}{$\mathbf{N}$} & \multirow[t]{3}{*}{$\%$} \\
\hline & \multicolumn{2}{|c|}{ Minipil } & \multicolumn{2}{|c|}{$\begin{array}{c}\text { Pil } \\
\text { Kombinasi }\end{array}$} & & \\
\hline & $\mathbf{n}$ & $\%$ & $\mathbf{n}$ & $\%$ & & \\
\hline $1-2 \mathrm{~kg}$ & 2 & 22,2 & 4 & 26,7 & 6 & 25 \\
\hline $2-3 \mathrm{~kg}$ & 2 & 22,2 & 2 & 13,3 & 4 & 16,7 \\
\hline $4-5 \mathrm{~kg}$ & 2 & 22,2 & 9 & 60 & 11 & 45,8 \\
\hline$>5 \mathrm{~kg}$ & 3 & 33,4 & 0 & 0 & 3 & 12,5 \\
\hline Total & 9 & 100 & 15 & 100 & 24 & 100 \\
\hline $\begin{array}{l}\text { mini pil } \\
5 \mathrm{~kg} \\
\text { akseptor } \\
\text { perubah }\end{array}$ & $\overrightarrow{a t}$ & $\begin{array}{l}\text { Drim } \\
\text { ran } \\
\text { va } \\
\text { lami } \\
3,49\end{array}$ & el & $\begin{array}{l}\text { terse } \\
\text { besa } \\
n \text { ber } \\
\text { ebas }\end{array}$ & $\begin{array}{l}\mathrm{d} \\
\mathrm{kse}\end{array}$ & \\
\hline
\end{tabular}

\section{Karakteristik Responden}

Hasil penelitian menunjukkan akseptor KB Pil paling banyak di usia 20-35 tahun, yaitu sebanyak 27 responden $(77,1 \%)$. Pada umur ini kebanyakan responden mempunyai 2 anak, yaitu 18 responden $(51,4 \%)$. Menurut Hartanto (2015) periode usia istri antara 20-35 tahun merupakan periode usia paling baik untuk melahirkan, dengan jumlah anak 2 orang dan jarak antara 
kelahiran adalah 2-4 tahun. Pada masa usia ini diperlukan jenis kontrasepsi yang mempunyai efektivitas cukup tinggi, reversibilitas cukup tinggi karena peserta masih mengharapkan punya anak lagi, dapat dipakai 2 sampai 4 tahun yaitu sesuai dengan jarak kehamilan anak yang direncanakan. Penelitian juga menunjukkan sebagian besar pendidikan responden adalah SMA yaitu $40 \%$, dalam hal ini menunjukkan pemilihan alat kontrasepsi KB pil berdasarkan pengetahuan dari akseptor.

Pemilihan KB Pil adalah pilihan rasional dibandingkan dengan $\mathrm{KB}$ lainnya selain cocok untuk usia ini, KB Pil cukup ekonomis sehingga dapat terjangkau di semua lapisan masyarakat. Hal inilah yang menjadi alasan mengapa pada usia lebih dari 30 tahun, dengan jumlah anak 2 lebih memilih KB Pil dibandingkan dengan jenis $\mathrm{KB}$ lainnya. KB Pil kesuburan mungkin baru kembali 1 tahun setelah konsumsi Pil dihentikan, tetapi KB Pil tidak menyebabkan kemandulan permanen. KB Pil bisa menyebabkan penambahan berat badan yang sifatnya ringan.

\section{Perubahan Berat Badan}

Dari hasil penelitian dapat diketahui bahwa rata-rata dari 14 responden akseptor KB Pil Oral Kombinasi yang mengalami kenaikan berat badan $<5 \mathrm{~kg}$ yaitu sebesar $35,7 \%$ dengan jumlah 6 responden dan yang mengalami kenaikan berat badan $\geq 5-10 \mathrm{~kg}$ yaitu sebesar $64,3 \%$ dengan jumlah 9 responden.

Menurut Meilani (2010) efek samping dari pemakaian Pil Oral Kombinasi antara lain perdarahan tidak teratur/terganggunya pola haid (spotting, amenorhea), nyeri tekan payudara, fluktuasi berat badan, mual, kembung, depresi. Menurut Hartanto (2015) hormon yang terkandung dalam kontrasepsi hormonal dapat merangsang pusat pengendali nafsu makan di hipothalamus yang menyebabkan akseptor makan lebih banyak dari biasanya. Diagnosa dari pertambahan berat badan pada pemakaian Pil Oral yaitu retensi cairan karena progestin atau estrogen di dalam Pil Oral, pertambahan berat badan yang disebabkan oleh estrogen mengakibatkan bertambahnya lemak subkutan terutama pada pinggul; paha; dan payudara; ini tampak setelah beberapa bulan minum Pil Oral, nafsu makan yang bertambah dan makan banyak (efek anabolik) disebabkan efek androgenik dari progestin, kadar insulin darah meninggi yang disebabkan oleh hormon progestin di dalam Pil Oral, intake kalori yang bertambah.

Menurut pendapat peneliti kenaikan berat badan Akseptor KB Pil Oral Kombinasi selain dari faktor di atas terdapat faktor-faktor lain yang menyebabkan meningkatnya berat badan. Faktor tersebut dibagi menjadi 2 yaitu faktor internal mencakup faktor-faktor hereditas seperti umur, gen dan regulasi termis. Faktor eksternal mencakup aktivitas fisik, dan asupan makanan.

Dari faktor umur berdasarkan hasil penelitian dapat diketahui bahwa sebagian besar responden berusia 20-35 tahun sebesar $77,1 \%$ dan sebagian kecil berusia $>35$ tahun sebesar 22,9\%. Selain karena umur meningkatnya berat badan juga dapat disebabkan oleh faktor gen dan regulasi termis.

Dari faktor eksternal yaitu faktor aktivitas fisik dan asupan makanan. Menurut Hartanto (2015) bila akseptor Pil Oral mengalami pertambahan berat badan oleh karena retensi cairan, kurangi estrogen atau progestin atau kedua-duanya. Kemudian pindah ke Pil Oral dengan potensi estrogen lebih rendah bila diketahui akseptor mengalami pertambahan berat badan yang disebabkan bertambahnya jaringan payudara dan lemak subkutan, terutama di pinggul dan payudara. Pertambahan berat badan umumnya bereaksi terhadap intake kalori yang dikurangi dan menambah latihan jasmani atau olahraga. Untuk menstabilkan berat badan dalam pemakaian Pil Oral Kombinasi harus diimbangi dengan menambah latihan jasmani atau olahraga. Beberapa ahli dari Amerika berdasarkan 
data penelitian tahun 2005 yakin bahwa kebiasaan hidup dan pola makan memegang faktor yang lebih dominan dalam memengaruhi berat badan seseorang bila dibandingkan faktor internal. Dua faktor eksternal yang sangat dominan adalah aktivitas fisik dan asupan nutrisi. Seseorang dapat dengan mudah mengurangi berat badannya tanpa perlu mengonsumsi obatobatan pembakar lemak dan semacamnya dengan meningkatkan aktivitas serta mengurangi asupan makanan ke dalam tubuhnya. Berdasarkan hasil penelitian dan teori di atas KB Pil Oral Kombinasi memang mempengaruhi peningkatan berat badan pada akseptor Pil Oral Kombinasi namun hal itu dapat diatasi dengan menggunakan KB Pil Oral Kombinasi dengan dosis yang lebih rendah, mengatur pola makan dan berolahraga secara teratur.

Hasil penelitian ini menunjukkan bahwa sebagian besar akseptor adalah pengguna pil kombinasi yaitu $65,7 \%$ dan hanya $34,3 \%$ yang menggunakan minipil. Dan dari 9 akseptor yang menggunakan mini pil, persentase terbesar mengalami kenaikan berat badan $>5 \mathrm{~kg}$ sedangkan dari 15 akseptor pengguna pil kombinasi, persentase terbesar mengalami kenaikan 4-5 kg.

Resiko kenaikan berat badan menurut Saifuddin (2006) kemungkinan disebabkan karena hormon progesteron mempermudah perubahan karbohidrat dan gula menjadi lemak, sehingga lemak di bawah kulit bertambah, selain itu hormon progesteron juga menyebabkan nafsu makan bertambah dan menurunkan aktivitas fisik, akibatnya pemakaian pil dapat menyebabkan berat badan bertambah.

Umumnya pertambahan berat badan tidak terlalu besar, bervariasi antara kurang dari $1 \mathrm{~kg}$ sampai $5 \mathrm{~kg}$ dalam tahun pertama konsumsi pil. Penyebab pertambahan berat badan tidak jelas.Tampaknya terjadi karena bertambahnya lemak tubuh, dan bukan karena retensi cairan tubuh. Hipotesa para ahli, hormon progesteron merangsang pusat pengendali nafsu makan di hipotalamus, yang menyebabkan akseptor makan lebih banyak dari biasanya (Hartanto, 2015).

Hasil penelitian juga menunjukkan sebagian besar kenaikan berat badan akseptor KB pil 4-5 $\mathrm{kg}$ yaitu $45,9 \%$, hanya $12,5 \%$ responden yang mengalami kenaikan berat badan $>5 \mathrm{~kg}$. Hasil penelitian ini menunjukkan adanya kesamaan dengan dugaan para ahli yang menyatakan umumnya pertambahan berat badan tidak terlalu besar bervariasi antara kurang dari $1 \mathrm{~kg}$ sampai $5 \mathrm{~kg}$ dalam tahun pertama konsumsi pil.

\section{KESIMPULAN}

Sebagian besar responden dengan umur 20-35 tahun yaitu $77,1 \%$, pendidikan SMA yaitu $40 \%$, jumlah anak 2 yaitu $51,4 \%$, tidak bekerja yaitu $71,5 \%$, menggunakan pil kombinasi yaitu $65,7 \%$, mengalami perubahan berat badan yaitu $68,6 \%$, kenaikan berat badan responden $4-5 \mathrm{~kg}$ yaitu $45,9 \%$, semua akseptor minipil mengalami perubahan berat badan $>5 \mathrm{~kg}$ yaitu $100 \%$ dan sebagian besar akseptor pil kombinasi mengalami perubahan berat badan $4-5 \mathrm{~kg}$ yaitu $81,8 \%$.

\section{SARAN}

Bidan dan petugas kesehatan lain dapat memberikan konseling tentang efek samping KB Pil sehingga tidak ada kekhawatiran dari akseptor KB tersebut.

\section{DAFTAR PUSTAKA}

Agustina Rohani, 2010. Hubungan Pemakaian Kontrasepsi Suntik Depo Progestin dengan Perubahan Berat Badan Di BPS Yuni Winarta Weru Sukoharj, Karya Tulis Ilmiah, Surakarta: Akademik Kebidanan Mamba'ul 'Ulum

BKKBN, (2010).Data Statistik KB Provinsi Jawa Tengah tahun 2002-2006, Biro Pusat Statistik Jawa Tengah, www.bps-jateng.go.id diunduh tanggal 18 Februari 2010 


\section{BKKBN,}

(2004).PedomanPenanggunglangan

efek samping/komplikasi

kontrasepsi.Jakarta: UNFTPA

BKKBN, (2002).Keluarga Berencana, http://riau.bkkbn.go.id/old/ diunduh tanggal 5 Maret 2010

Hartanto H. 2004. Keluarga Berencana dan Kontrasepsi.Jakarta : Pustaka Sinar Harapan

Manuaba, I. B. G. (2001).Kapita Selekta Pentalaksanaan Rutin Obstetri Ginekologi dan KB.Jakarta: EGC

Saifuddin, ddk.(2003). Buku Panduan Praktis Pelayanan Kontrasepsi.Jakarta: Yayasan Bina Pustaka Sarwono Prawirohardjo

Winkjosastro, H. (2005). Ilmu Kandungan. Jakarta: Yayasan Bina Pustaka Sarwono Prawirohardjo 